Glud, J.A., Overgaard, L.C.T., Dulieu-Barton, J.M., and Thomsen, O.T., “Automated counting of off-axis tunnelling cracks using digital image processing" Composites

Science and Technology, 125, 2016, 80-89. http://dx.doi.org/10.1016/j.compscitech.2016.01.019

\title{
Automated counting of off-axis tunnelling cracks using digital image processing
}

\author{
J.A. Glud ${ }^{1}$, J.M. Dulieu-Barton ${ }^{1,2}$, O.T. Thomsen ${ }^{1,2}$ and L.C.T. Overgaard ${ }^{1}$ \\ ${ }^{1}$ Department of Mechanical and Manufacturing Engineering, Aalborg University \\ Fibigerstraede 16, 9220, Aalborg Oest, Denmark \\ Email: \{jag,ott,lcto\}@m-tech.aau.dk, web page: www.m-tech.aau.dk \\ ${ }^{2}$ Faculty of Engineering and the Environment, University of Southampton \\ Highfield, SO17 1BJ, Southampton, United Kingdom \\ Email: \{janice,o.thomsen\}@soton.ac.uk, web page: www.southampton.ac.uk/engineering
}

Keywords: Fatigue, Polymer-matrix composites, Matrix cracking, Damage mechanics, Digital image processing

\begin{abstract}
An automated method for counting propagating matrix tunnelling cracks for use in mechanical testing of Glass Fibre Reinforced Plastic (GFRP) laminates under quasi-static and fatigue loading is presented. White light images are captured from specimens during the loading. The transmitted light is used to detect the cracks in the images, which are then processed to count the cracks as they develop and grow through the duration of the test. The reproducibility and accuracy of the image processing is demonstrated using simulated transverse crack densities and patterns. The methodology is demonstrated and validated experimentally using two different laminate stacking sequences of the type $[0 /-\theta / 0 / \theta]_{\text {s. }}$ The results related to the crack density evolution are shown to be consistent with results from the literature.
\end{abstract}

\section{Introduction}

For more than four decades, fatigue life prediction for composite laminates subjected to multiaxial loading has been a subject of significant interest due to the increasing use of composite materials in many industrial applications. The nature of fatigue damage in composite laminates is complicated, as many cracks initiate, propagate and coalesce, making mechanistic modelling challenging. Therefore the vast majority of fatigue life prediction models are phenomenological, e.g. [1], [2], [3], [4]. These models are based on the assumptions adopted in [5], where failure of laminated composites can only occur in the fibres and matrix. The models attempt to predict when the failure modes occur and how they influence structural behaviour, thereby taking into account the physical damage mechanisms in a simplistic way. A recent extensive review of phenomenological multiaxial 
Glud, J.A., Overgaard, L.C.T., Dulieu-Barton, J.M., and Thomsen, O.T., “Automated counting of off-axis tunnelling cracks using digital image processing” Composites

Science and Technology, 125, 2016, 80-89. http://dx.doi.org/10.1016/j.compscitech.2016.01.019

fatigue criteria [6] has shown that for some multiaxial load cases the models gave non-conservative predictions. Due to the phenomenological nature of the models, no apparent reason for the large discrepancies between model predictions and experimental observations can readily be obtained, which further questions their general validity. Therefore, in [6] it is emphasised that there is an urgent need for developing an improved understanding of the underlying damage mechanisms, alongside the inclusion of physical damage mechanisms in predictive multiaxial fatigue models. Many kinds of micro damage may evolve during the fatigue life of laminated composites. One of the most common damage modes is intralaminar cracks in the laminate layers, which are throughthe-thickness (tunnelling) cracks in the matrix and fibre debonds propagating along the fibres. These cracks are commonly called transverse and off-axis matrix cracks. Defining the material damage state in terms of off-axis cracks provides an important parameter, which is a true physical internal state variable that can be treated using the well-developed framework of fracture mechanics. Several analytical models for predicting the stiffness degradation as function of the offaxis crack state in each laminate layer have been proposed, see e.g. [7-9], but widely accepted models describing the initiation and evolution of off-axis cracks during fatigue loading of multidirectional laminates are yet to be proposed. This may be attributed to the tedious and labour intensive work required to define the damage state, which predominantly up until now has been accomplished by manually counting the propagating cracks. The mainly manual and very labour intensive damage characterisation process has so far limited the scope and size of experimental campaigns, and/or significant data parameterisation, which makes it difficult to draw firm conclusions and to derive statistically representative material parameters. The overarching aim of the present research is therefore the development of a robust and accurate method for automatic quantification of the damage in GFRP laminates in terms of off-axis cracks. The development of such a methodology will enable the efficient and accurate determination of physical damage state parameters, and this is a prerequisite for the development and validation of more reliable off-axis crack evolution models.

\subsection{Off-axis Crack State Detection}

Several experimental measurement methods have been used to successfully detect off-axis cracks in GFRP laminates. The diverse selection of techniques include thermoelastic stress analysis (TSA) [10], digital image correlation (DIC) [11], acoustic emission [12], X-ray [13], X-ray Computed Tomography (CT) [14], Ultrasonic C-scan [13] and transilluminated white light imaging (TWLI) 
Glud, J.A., Overgaard, L.C.T., Dulieu-Barton, J.M., and Thomsen, O.T., “Automated counting of off-axis tunnelling cracks using digital image processing” Composites

Science and Technology, 125, 2016, 80-89. http://dx.doi.org/10.1016/j.compscitech.2016.01.019

[15-19]. X-ray, X-ray CT and Ultrasonic C-scan require the fatigue test to be interrupted to conduct measurements and are not relevant in the context of the present research. TSA and DIC can be used to obtain in-situ surface measurements of the sum of maximum principal stresses and the component strain fields respectively. However, depending on the laminate layup the stress/strain redistribution on the surface caused by the presence of a crack may be below the strain resolution of the methods. Furthermore, the number of independent measurement points is very limited compared to TWLI. Acoustic emission is an in-situ and automated measurement method [12], but the damage mode connected with acoustic events has to be hypothesised or calibrated with other techniques. TWLI as used in [15-19] represents a cheap, fast and data-rich in-situ detection method for GFRP laminates because of their transparent nature, which permits transmitted white light to be used as a means of detecting cracks. Based upon the above reasoning TWLI was found to be the most favourable method for crack detection, and accordingly was chosen as the basis for this research.

\subsection{Off-axis Crack State Quantification}

TWLI works by illuminating the material from one side and then acquiring images of the light transmitted through the material from the other side. The transmission of light is disrupted by the presence of off-axis cracks making them visible in the acquired images. A significant limitation of TWLI is that it is restricted to transparent materials (like GFRP). Previous research that has utilised TWLI for counting off-axis cracks includes little or no automation of the procedure. In [19] an automatic acquisition and crack counting system for in-situ transverse crack counting was developed. However, spatial information on the crack pattern perpendicular to the loading direction was neglected, which means that the method is limited to counting the number of transverse cracks, and not the length and location of each individual crack. In [15] the automatic crack counting system was used to count transverse cracks in two different laminates. The same authors [16] studied off-axis cracks, but due to the limitations of their method they had to resort to manual quantification of the damage state in terms of crack initiation and crack saturation from images acquired using a video camera and in-situ microscopic edge examination. Off-axis cracks in multiaxially loaded tubes made from non-crimp GFRP fabrics were studied [17] and the damage state quantified in terms of crack densities at different lifetimes. Crack density measurements were conducted by interrupting the fatigue tests and then acquiring images of the cracks using a light microscope upon several areas of interest and the off-axis cracks were counted by visual inspection of the images. Off-axis cracks in flat coupon test specimens made from GFRP prepreg were studied 
Glud, J.A., Overgaard, L.C.T., Dulieu-Barton, J.M., and Thomsen, O.T., “Automated counting of off-axis tunnelling cracks using digital image processing” Composites

Science and Technology, 125, 2016, 80-89. http://dx.doi.org/10.1016/j.compscitech.2016.01.019

in [18] using backlight illumination and a standard SLR camera to automatically acquire images of the off-axis cracks throughout the fatigue life of the specimens ${ }^{1}$. The damage state and evolution were quantified in terms of crack density and crack growth rate (CGR) of isolated cracks. The crack density was counted manually by dividing cracks into eight separate bins. The reason for this was to ease the manual counting process. The CGR measurements were obtained by manually measuring the length of isolated cracks at different numbers of cycles. From the above literature review, it is clear that a means of automatically counting both transverse and off-axis cracks is essential to avoid tedious manual work and avoid human errors in the counting process, enabling reproducible results that are obtained in a fast and reliable manner.

\subsection{Translaminar Crack State Qualification}

A novel algorithm for qualification of translaminar crack state called Automated Crack Counting (ACC) to automatically detect, monitor and measure the length and position of each observable crack layerwise in GFRP laminates with arbitrary layup is presented. ACC uses TWLI to detect and track cracks and digital image processing to filter images. The image filtering serves two purposes; 1) produce a clear image of the cracks, and 2) to filter out cracks from other layers to define the crack state layerwise instead of laminate-wise. The length and location of each individual crack is measured from the filtered images using a simple heuristic procedure. The new ACC procedure is validated based on simulated crack densities which are used to benchmark ACC against a known input, and to provide guidelines for the choice of measuring volume versus expected crack density. Furthermore, the ability of the ACC to detect and measure cracks in their full length is validated against microscopic examination. Results from fatigue tests of two different GFRP laminates are presented, which represent challenging test cases, because they are made from stitched fibre mats and vacuum assisted resin transfer moulding used for e.g. wind turbine blade laminates. The stitching thread has a different refractive index than the glass fibres and matrix material, so the stitching thread appears as a texture in the material, which exacerbates crack counting. It is shown that ACC allows for fast, accurate and reproducible detection as well as unprecedented quantification of the translaminar crack state.

\footnotetext{
${ }^{1}$ In [18] it is not stated when the images were acquired during the fatigue tests. At Comptest2015, 8-10th of April 2015, Madrid, M. Quaresimin (corresponding author of [18]) elaborated on the experimental procedure in a private discussion, and informed that the test specimens were unloaded each time an image was acquired. Hereafter the test was recommenced.
} 
Glud, J.A., Overgaard, L.C.T., Dulieu-Barton, J.M., and Thomsen, O.T., “Automated counting of off-axis tunnelling cracks using digital image processing” Composites

Science and Technology, 125, 2016, 80-89. http://dx.doi.org/10.1016/j.compscitech.2016.01.019

\section{Automated Crack Counting methodology}

An image and a sketch of the experimental setup used for fatigue testing of GFRP laminates and acquiring in-situ images of off-axis cracks using TWLI are shown in Figure 1a. A digital camera is placed on one side of the specimen and the backlight illumination on the other side. The specimen is also illuminated on the front side for the purposes of image compensation. Figure 1b illustrates the specimen geometry along with important features on the specimen and Table 1 summarises the properties of the optical system.

\begin{tabular}{|c|c|c|c|c|c|}
\hline Camera & Camera Resolution & Lens & $\begin{array}{c}\text { Exposure } \\
\text { time }\end{array}$ & $S N R=20 \log \left(\frac{\text { signal }}{\text { RMS noise }}\right)$ & $\begin{array}{c}\text { Lens } \\
\text { Distortion } \\
\text { Calibration }\end{array}$ \\
\hline $\begin{array}{c}\text { Imager } \\
\text { E-Lite } \\
5 \mathrm{M}\end{array}$ & $5 \mathrm{MPixel}$ & $\begin{array}{c}\text { Sigma } \\
105 \mathrm{~mm} \\
\text { Macro }\end{array}$ & $600 \mu \mathrm{s}$ & $>24 \mathrm{~dB}$ & Not used \\
\hline
\end{tabular}

Table 1: Specifications for the optical system.

The RMS noise used for computing the signal-to-noise ratio (SNR) was determined by subtracting two reference images and then calculating the root mean square value for the entire pixel set. Figure 2a and Figure 2b provide examples of acquired images for a $4.3 \mathrm{~mm}$ thick laminate made from unidirectional stitched fibre mats with an areal weight of $600 \mathrm{~g} / \mathrm{m}^{2}$. The layup is $[0 /-60 / 0 / 60]_{\mathrm{s}}$ and the 0 plies are oriented along the $\mathrm{x}$-axis in the figures. In Figure 2a there is no damage in the material, so the image provides a reference image. Figure 2b shows off-axis cracks developed in the off-axis plies, which is considered to be an in-situ image of the damage state. The texture caused by the stitching thread is highlighted with a blue colour in Figure 2a, and by comparing Figure 2a and Figure $2 \mathrm{~b}$ it is evident that the texture caused by the stitching could make reliable crack counting difficult. The intensity profile in the images defined by the stitching does not change as off-axis cracks develops, hence to study the damage evolution it would be beneficial to compare the image of the in-situ image with the reference image. However, the measuring volume in the in-situ images has undergone rigid body motion as well as deformation. In order to compare the in-situ images with the reference image an image compensation procedure is required for the in-situ images. The in-situ image compensation should allow for both rigid body motion and deformation in the in-situ images, so identical and static features, e.g. stitching thread, in the reference image and the compensated in-situ image have the same shape and pixel location. The image compensation removes identical and static features unrelated to crack growth. Furthermore to obtain the layer- 
Glud, J.A., Overgaard, L.C.T., Dulieu-Barton, J.M., and Thomsen, O.T., “Automated counting of off-axis tunnelling cracks using digital image processing” Composites

Science and Technology, 125, 2016, 80-89. http://dx.doi.org/10.1016/j.compscitech.2016.01.019

wise crack state image filtering is required to identify the separate layers of the laminate.

Consequently the ACC procedure consists of three main operations:

1 Image compensation

2 Image filtering

3 Crack counting

\subsection{Image Compensation}

For the image compensation procedure it is necessary to identify a feature in each corner of the image that is within the camera's Field of View (FoV) throughout the test. Figure 2a shows the measuring volume with the features, i.e. the four crosses $(+)$, positioned at each corner. The crosses were applied by painting the areas with white spray paint and then scratching crosses in the paint. Tape was applied to the backside of the specimens at the location of the crosses to avoid penetrating back light illumination from being transmitted through the features. Front light illumination was used so that the camera could observe the four features in each corner of the FoV.

The first part of the image compensation is to determine the displacement of the four features from the reference image to the in-situ image. The procedure is sketched in Figure 3 and it utilises normalised cross-correlation $c$ [20] as follows:

$$
c(u, v)=\frac{\sum_{x, y}\left(I^{i}(x, y)-\bar{I}_{u, v}^{i}\right)\left(I_{s}^{r}(x-u, y-v)-\bar{I}_{s}^{r}\right)}{\sqrt{\sum_{x, y}\left(I^{i}(x, y)-\bar{I}_{u, v}^{i}\right)^{2} \sum_{x, y}\left(I_{s}^{r}(x-u, y-v)-\bar{I}_{s}^{r}\right)^{2}}}
$$

where $I^{r}$ refers to the intensity in the reference image, the subscript $s$ denotes a subset of the image (sub-image of each cross), $I^{i}$ is the intensity of the in-situ image, the overbar represents the mean intensity in the image, and $u$ and $v$ are displacements in the $x$ and $y$ directions, respectively. $c$ is a matrix containing normalised cross-correlation values for different displacements of the subset of image $I_{S}^{r}$. Therefore the row and column position of the maximum entry in $c$ corresponds to the most likely displacements $u$ and $v$, respectively. To save computational effort, the cross correlation is only calculated on sub regions of the in-situ image, which are marked by blue dashed squares in Figure 3. Before the normalised cross-correlation values are computed, the resolution of the subset of image $I_{s}^{r}$ and the subregions are increased by a factor two using bilinear interpolation. This is done to obtain subpixel displacement accuracy. A linearly varying displacement field is assumed and the displacement field in direction $u(x, y)$ and $v(x, y)$ can be obtained by fitting a bilinear function to the obtained displacements. Knowing the displacement field it is possible to compensate 
Glud, J.A., Overgaard, L.C.T., Dulieu-Barton, J.M., and Thomsen, O.T., “Automated counting of off-axis tunnelling cracks using digital image processing” Composites

Science and Technology, 125, 2016, 80-89. http://dx.doi.org/10.1016/j.compscitech.2016.01.019

for the rigid body motion and deformation experienced by the specimen in the in-situ image. This is done using the inverse linear transformation given as

$$
I^{u}(x, y)=(T)^{-1} I^{i}(x, y)=\left[\begin{array}{ccc}
1+\frac{\partial u}{\partial x} & \frac{\partial u}{\partial y} & u(0,0) \\
\frac{\partial v}{\partial x} & 1+\frac{\partial v}{\partial y} & v(0,0) \\
0 & 0 & 1
\end{array}\right]^{-1} I^{i}(x, y)
$$

where $I^{u}$ represents the in-situ image after the inverse linear transformation has been applied. The last step in the image compensation is to normalise the compensated in-situ image with the reference image following

$$
I^{d}(x, y)=\frac{I^{u}(x, y)}{I^{r}(x, y)}
$$

where $I^{d}$ is the normalised image. Figure 4a shows an example of $I^{d}$ and it is seen that the normalisation removes the texture from the stitching thread, so that the off-axis cracks appear much clearer than in the raw image shown in Figure $2 \mathrm{~b}$.

\subsection{Image Filtering}

The next step is to filter the images such that cracks in different layers (orientations) can be studied independently of cracks in adjacent layers. Gabor-filtering [21] was found to give consistent and reproducible results for this type of problem. The Gabor-filtering mask is generally built from five user inputs $\left(\lambda, \gamma, \varphi, \sigma_{G}, \theta\right)$. For the problem at hand only four parameters were used and this was $\lambda, \gamma, \sigma_{G}$ and $\theta$. The parameters $\lambda, \gamma$ and $\sigma_{G}$ are related to the spatial size of the lines searched for and must be manually adjusted according to one image, see Figure 4a, so that cracks are the only features identified in the image. The manual adjustment process is only carried out once, and the chosen parameters can then be used for all layers and other test specimens. The parameter $\theta$ represents the orientation perpendicular to these lines and is hence defined by the stacking sequence. The parameter $\varphi$ mentioned above is not used/specified here, since the detection of cracks was insensitive to this parameter. The results of filtering the image for each of the two crack orientations are shown in Figure 4b. The Gabor filtering produces a clean image of the cracks in the defined orientation and captures nearly all cracks over their full length in the filtered image. 
Glud, J.A., Overgaard, L.C.T., Dulieu-Barton, J.M., and Thomsen, O.T., “Automated counting of off-axis tunnelling cracks using digital image processing” Composites

Science and Technology, 125, 2016, 80-89. http://dx.doi.org/10.1016/j.compscitech.2016.01.019

\subsection{Crack Counting}

It is difficult to create a heuristic procedure for the crack counting from the images produced by the Gabor filter for several reasons. The intensity values are floating point numbers, so a threshold must be chosen to distinguish between crack, background and (ambient) image noise. Furthermore, it is seen that the cracks have different apparent widths meaning that one single heuristic criterion is insufficient to count all cracks. Therefore thresholding, based on the Otsu's Method [22], was used to compute binary images from the filtered images. Hereafter a thinning of the cracks is carried out using the thinning algorithm presented in [23] such that one pixel thick lines are obtained.

The result of the thresholding along with thinning is shown in Figure 5. The crack counting is further facilitated by rotating the images obtained from the thinning such that cracks are oriented vertically as seen in Figure 6. Now the counting is simply carried out by searching each row of the image (from row one to the final row) for a pixel indicating a crack start (black pixel). The column belonging to the crack start pixel is then searched row wise from the entry of the crack start pixel to the final row of the column (last row of the image) for more black pixels. A crack end is found, when a white pixel is met. Cracks may not be perfectly aligned with columns due to fibre misalignment, so the heuristic procedure can shift to a neighbouring column by searching the two neighbouring columns for a black pixel. The heuristic procedure then proceeds along the column with the found black pixel until only white pixels are found. The robustness of the developed ACC procedure with respect to fibre misalignment will be discussed further in section 4 . The location of the start and end point of the crack are saved, the crack deleted (changing the colour of the found black pixels into white) and the image scanned for the next crack. This procedure continues until there are no further cracks in the image. The saved start and endpoints are then transformed into their reference coordinate system.

To validate the methodology the counted cracks were plotted on the image given in Figure 4a and are shown in Figure 7. It can be seen that virtually all the cracks are counted to their full length and have the proper orientation and location, hence it is concluded that the ACC procedure works as intended. A few short cracks that are not captured by the algorithm are highlighted with dashed circles in Figure 7. These cracks are captured by the ACC when the cracks have grown further; for this particular test this occurred in the next processed image. It should be noted that delaminations between layers/plies may hide cracks, since delaminations will appear as dark regions in the filtered image. Consequently, as delaminations evolve ACC may count a reducing number of cracks. In 
Glud, J.A., Overgaard, L.C.T., Dulieu-Barton, J.M., and Thomsen, O.T., “Automated counting of off-axis tunnelling cracks using digital image processing” Composites

Science and Technology, 125, 2016, 80-89. http://dx.doi.org/10.1016/j.compscitech.2016.01.019

order to avoid this problem ACC saves already counted cracks from previously analysed images, add these cracks to subsequent images and then search for new cracks. However, new cracks forming in areas of delamination cannot be seen and this is a limitation of the proposed ACC methodology.

\section{Definition of crack density}

The most common way to quantify the damage state in terms of transverse and off-axis cracks is through the crack density parameter. The crack density is defined as the number of cracks divided by the length of the observation zone, measured perpendicular to the propagation direction [24]. This definition only takes into account the number of cracks and not the length of the cracks. As highlighted in $[8,18,25]$, it is preferable to include the crack length in the definition so the crack density is directly proportional to the crack surface area within the material, as this will provide a better description of the damage state. The crack density definition used throughout this paper is defined as

$$
\rho=\frac{\sum_{i=1}^{n} L_{c r a c k}^{i}}{A R E A}
$$

where $A R E A$ refers to the area of the rectangular measuring volume and $L_{\text {crack }}^{i}$ is the length of the ith crack. It should be noted that Equation (4) is consistent with the crack density definition found in [18].

\section{Numerical Validation}

A series of benchmarks have been carried out to test the reproducibility and accuracy of the filtering and counting part of the proposed ACC procedure, and to provide guidelines on the choice of measuring volume. Artificial images of specimens with perfectly aligned off-axis cracks were generated, so that the midpoints of the simulated cracks follow a uniform distribution in the field of view and the length of each crack follows a normal distribution $\left(\mu_{n}, \sigma_{n}\right)$. An image of computer generated transverse and off-axis cracks for a layup of [-45/45/90] is shown in Figure 8. The distance between the crack centers $\left(W_{s}\right)$ was chosen to 20 pixels as this was less than the minimum observed distance between cracks in the experiments. The width of each crack $\left(W_{c}\right)$ was chosen to be five pixels, which was found to be the minimum apparent width of cracks observed in the experiments. In Figure 9 the counted cracks are overlaid with semi-transparent lines in the same base colour. It is observed that all cracks are captured, however for some cracks a small mismatch 
Glud, J.A., Overgaard, L.C.T., Dulieu-Barton, J.M., and Thomsen, O.T., “Automated counting of off-axis tunnelling cracks using digital image processing” Composites

Science and Technology, 125, 2016, 80-89. http://dx.doi.org/10.1016/j.compscitech.2016.01.019

between the actual crack front and the crack front identified by the ACC algorithm is observed. The parameters given in Table 2 were used for all numerical simulations.

\begin{tabular}{|c|c|c|}
\hline $\begin{array}{c}\mathrm{h} \text { (Image Height) } \\
{[\text { Pixel] }}\end{array}$ & $\begin{array}{c}\mathrm{w} \text { (Image Width) } \\
{[\text { Pixel] }}\end{array}$ & $\begin{array}{c}\text { Minimum Crack Spacing } \\
\left(W_{s}\right) \text { [Pixel] }\end{array}$ \\
\hline 1266 & 1940 & 20 \\
\hline $\begin{array}{c}\text { Crack Width }\left(W_{c}\right) \\
{[\text { Pixel] }}\end{array}$ & $\begin{array}{c}\mu_{n} \text { (Mean Crack Length) } \\
\text { [Pixel] }\end{array}$ & $\begin{array}{c}\sigma_{n} \text { (Crack Length Std } \\
\text { Deviation) } \\
{[\text { Pixel] }}\end{array}$ \\
\hline 5 & $\frac{h}{2 \sin (\alpha)}$ & $\frac{h}{4 \sin (\alpha)}$ \\
\hline$\theta\left[{ }^{\circ}\right]$ & $\gamma$ & $\sigma_{G}[$ Pixel] \\
\hline$\alpha-90$ & 0.1 & 10 \\
\hline$\lambda[$ Pixel] & $\varphi[$ Pixel] & \\
\hline 22 & 0 & \\
\hline
\end{tabular}

Table 2: Properties used for the numerical simulation unless otherwise specified. The angle $\alpha$ refers to the orientation of the crack in the investigated layer.

The first benchmark compares the counted crack density with the crack density of the artificial images for five different patterns ([-45], [-45/45], [-45/45/90], [-30/30] and [-60/60]). The reason for choosing the five different patterns is to demonstrate the ability of the ACC method to accurately count cracks for a variety of different layups, and to show that the ACC method is capable of counting cracks which lay beneath other cracks. In Figure 10 the relative error for each layup is plotted as function of the crack density. For layups with more than one layer, the relative error plotted is the sum of the relative error of each layer. As can be seen the ACC algorithm counts cracks for a wide range of patterns within -3 to $1.5 \%$ accuracy. Hence accuracy is not decreased when more layers are added. In general the ACC algorithm calculates a crack density that is slightly lower than the actual crack density. This phenomenon is caused by the Gabor filtering where the filtered crack front is behind the actual crack front. The error is decreased as the crack density is increased due to the fact that the average length of the cracks increases. This means that if the (small) mismatch between the counted and actual crack fronts is small compared to the length of the 
Glud, J.A., Overgaard, L.C.T., Dulieu-Barton, J.M., and Thomsen, O.T., “Automated counting of off-axis tunnelling cracks using digital image processing” Composites

Science and Technology, 125, 2016, 80-89. http://dx.doi.org/10.1016/j.compscitech.2016.01.019

crack, then the relative error is very small as well, so the relative error will reduce with increasing crack length.

The choice of composite laminate production method and fibre mat architecture has a significant influence on the degree of fibre misalignment. Off-axis cracks follow the direction of the fibres and the result of fibre misalignment is that cracks are oriented differently than expected from the nominal fibre orientations specified for the laminate. The motivation for the second benchmark is therefore to demonstrate that the ACC method is capable of handling mismatch between user specified (or nominal) and actual layup angles. As seen from Figure 11a the ACC algorithm is capable of counting cracks that are orientated at $\pm 6^{\circ}$ different from the nominal angle without increasing the relative error. A tolerance of $\pm 6^{\circ}$ is well within the achievable tolerances of the most common composite production methods (hand-layup, VARTM, prepreg, filament winding, pultrusion etc.). Accordingly, it is concluded that the ACC method can be considered sufficiently robust for practical purposes.

The Gabor filtering may filter out cracks if the minimum crack spacing ( $W_{s}$ in Figure 8 ) becomes too small, as the Gabor filter is bandwidth limited. The bandwidth is determined by the choice of Gabor parameters $\left(\lambda, \gamma, \sigma_{G}\right)$. When the minimum crack spacing gets smaller, the localised spatial frequency of cracks increases and the result of the bandwidth limitation is that cracks may be filtered out. The purpose of the third benchmark is therefore to study the relative error of the crack counting when the minimum allowed crack spacing is reduced. The relative error versus the spacing ratio is plotted in Figure 11b. Referring to Figure 11b, the spacing ratio, $r_{c s}$, is defined as $r_{c s}=$ $W_{s} / W_{c}$. It is observed that the ACC algorithm misses the majority of cracks at a spacing ratio of less than 2. At a ratio of 2.2 the ACC algorithm finds all cracks, and the error in terms of crack density is less than $1 \%$. Changing the FoV of the camera does not influence the spacing ratio. Accordingly, as a practical consequence of the chosen Gabor parameters the ACC algorithm has only been shown to work for materials/laminates where the spacing ratio is 2.2 or more. Adjusting the Gabor parameters or enhancing the image filtering may improve the ACC algorithms ability to measure cracks with a lower spacing ratio. For a known camera resolution, a rule of thumb for choosing an appropriate size of the measuring volume $(w, h)$ to achieve a robust counting is proposed as

$$
\left\{\begin{array}{l}
w \\
h
\end{array}\right\} \leq \frac{l_{c}}{P_{c}}\left\{\begin{array}{l}
P_{x} \\
P_{y}
\end{array}\right\}=\frac{l_{c}}{\left(W_{s}+W_{c}\right)}\left\{\begin{array}{l}
P_{x} \\
P_{y}
\end{array}\right\}=\frac{1}{\left(1+r_{c s}\right) \cdot W_{c} \cdot \rho_{\max }}\left\{\begin{array}{l}
P_{x} \\
P_{y}
\end{array}\right\}
$$


Glud, J.A., Overgaard, L.C.T., Dulieu-Barton, J.M., and Thomsen, O.T., “Automated counting of off-axis tunnelling cracks using digital image processing" Composites

Science and Technology, 125, 2016, 80-89. http://dx.doi.org/10.1016/j.compscitech.2016.01.019

where $P_{x}, P_{y}$ are the horizontal and vertical number of CCD pixels, respectively, $P_{c}$ is the number of pixels required to identify a crack and separate it from other cracks, $l_{c}$ is the physical distance between cracks, and is the inverse of the crack density. $\rho_{\max }$ is the expected maximum crack density and according to [26] it is reasonable to assume $\rho_{\max }=\frac{1}{t_{k}}$ for internal layers, and $\rho_{\max }=$ $\frac{1}{2 t_{k}}$ for external layers, where $t_{k}$ is the thickness of the cracked layer. $W_{c}$ represents the apparent crack width aimed for measured in pixels (See Figure 8). It can be expected that more pixels per crack width will give a more robust counting, but the downside is a reduction in the measuring volume. In this research it was found that 5 pixels per crack width gave a robust counting of cracks. It is also important to note that Equation (5) does not account for specimen geometry and orientation of the measuring volume with respect to the crack propagation direction.

\section{Experimental Validation \& Results}

Two GFRP laminates were fabricated for the experimental validation of the proposed ACC methodology. The laminates were made from stitched unidirectional glass fibre mats using handlayup and vacuum assisted resin transfer moulding. The matrix material was epoxy and the layup of the two laminates were $[0 /-60 / 0 / 60]_{\mathrm{s}}$ and $[0 /-30 / 0 / 30]_{\mathrm{s}}$, where the 0 degree plies were oriented along the $\mathrm{x}$-axis in Figure 1b. All laminates were cut using water jet cutting. Tensile specimens were cut from the manufactured laminates plates and the tests were conducted in an Instron 8820 load frame with a $100 \mathrm{kN}$ servo-hydraulic actuator operated in load control. One specimen from each laminate was tested, and the geometry of the specimens, mechanical properties, the applied loading (tensile) amplitude and mean value, stress ratio, loading frequency and cycles at the end of the testing are given in Table 3. The fibre volume fractions were determined by means of burn-off tests.

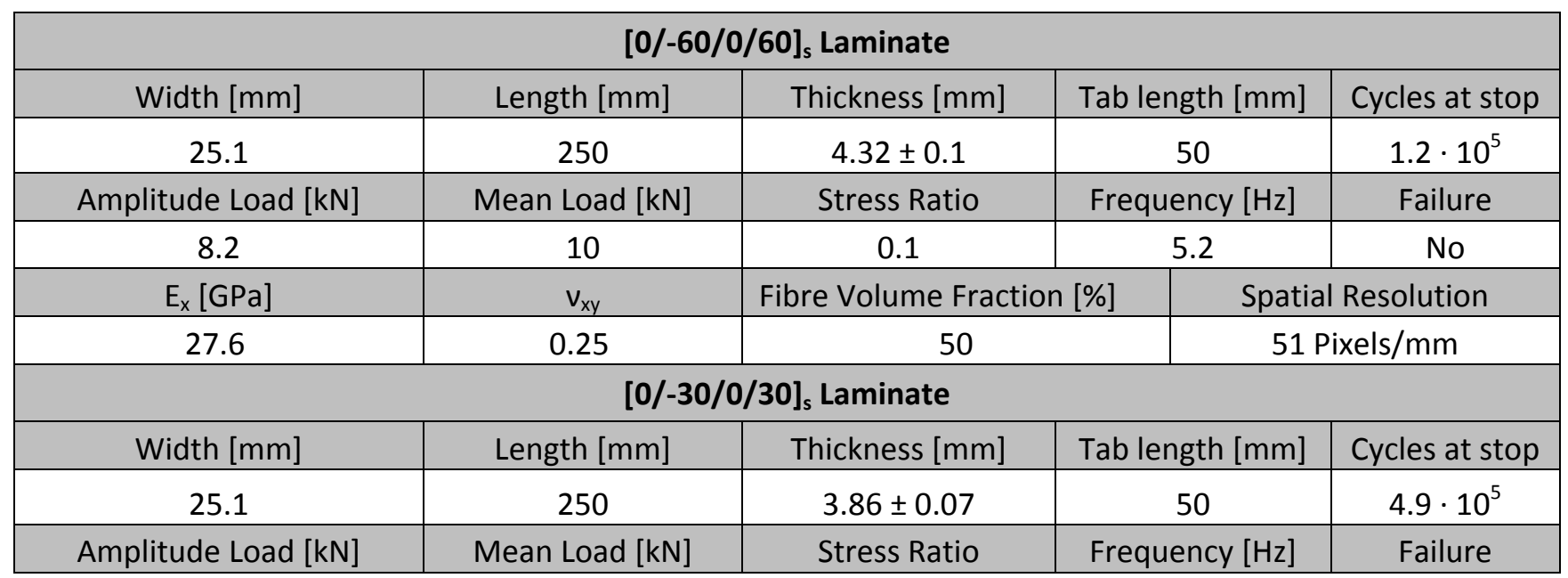


Glud, J.A., Overgaard, L.C.T., Dulieu-Barton, J.M., and Thomsen, O.T., “Automated counting of off-axis tunnelling cracks using digital image processing" Composites

Science and Technology, 125, 2016, 80-89. http://dx.doi.org/10.1016/j.compscitech.2016.01.019

\begin{tabular}{|c|c|c|c|c|}
\hline 8.2 & 10 & 0.1 & 5.2 & No \\
\hline $\mathrm{E}_{\mathrm{x}}[\mathrm{GPa}]$ & $v_{x y}$ & Fibre Volume Fraction [\%] & \multicolumn{2}{|c|}{ Spatial Resolution } \\
\hline 32.9 & 0.35 & 55 & \multicolumn{2}{|c|}{52 Pixels/mm } \\
\hline
\end{tabular}

Table 3: Properties for the fatigue tests on the [0/-60/0/60]s and [0/-30/0/30]s laminates. The off-axis cracks in the [0/-60/0/60 $]_{s}$ laminate were examined using a microscope to determine if the FoV of the camera was chosen appropriately and if the ACC algorithm captured the cracks properly. A comparison between the compensated in-situ image, the compensated image overlaid with counted cracks and the image obtained using a microscope at 4x zoom is shown in Figure 12. All cracks in the area of interest are captured by the ACC algorithm even though the local crack density is high in the -60 degree layer $(\approx 2[\mathrm{cracks} / \mathrm{mm}])$. From the microscopic examination, Figure 12b, it is further observed that crack splitting is evident. Crack splitting is not captured by the ACC algorithm and is not a failure mode of interest for the present work. In Figure 13 the counted cracks at the end of the fatigue tests are shown for the $[0 /-60 / 0 / 60]_{\mathrm{s}}$ and $[0 /-30 / 0 / 30]_{\mathrm{s}}$ laminates, respectively. The cracks in the -60 degree layer the farthest away from the camera could not be detected. These cracks are not detectable by eye either, unless the laminate is examined from the backside. This may be attributed to the stitching thread resulting in a high degree of light scatter, which removes the shadow caused by these cracks. The crack density for the [0/-60/0/60] laminate is 0.69 [cracks $/ \mathrm{mm}$ ] $\left(0.0013\right.$ [cracks/pixel]) in the $60^{\circ}$ layer and 1.03 [cracks $/ \mathrm{mm}$ ] $(0.02$ [cracks/pixel]) in the $-60^{\circ}$ layer. The crack density for the $[0 /-30 / 0 / 30]_{\mathrm{s}}$ laminate is 0.35 [cracks $/ \mathrm{mm}$ ] (0.0068 [cracks/pixel]) in the $30^{\circ}$ layer and 0.59 [cracks/mm] (0.011 [cracks/pixel]) in the $-30^{\circ}$ layer. It is evident that the vast majority of the cracks are captured for both laminates. The crack density derived using ACC and manual counting for the two laminates as function of the number of cycles is shown in Figure 14. Manual counting and ACC agree very well, and the evolution of crack density as measured by the ACC procedure is similar to evolution curves found in literature, e.g. [16-18]. It is observed that the crack density increases rapidly in the first part of the cyclic loading. The steep gradient observed in the curves of the crack density vs. number of cycles reduces significantly with increasing number of cycles, and it is hypothesised that a crack density saturation limit will be reached even though the current tests were stopped before this occurred. 
Glud, J.A., Overgaard, L.C.T., Dulieu-Barton, J.M., and Thomsen, O.T., “Automated counting of off-axis tunnelling cracks using digital image processing" Composites

Science and Technology, 125, 2016, 80-89. http://dx.doi.org/10.1016/j.compscitech.2016.01.019

\section{Conclusions}

A novel method based on digital image processing for the qualification of transverse and off-axis cracks (tunnelling cracks) in GFRP laminates has been presented. The method, referred to as the Automated Crack Counting (ACC) method, is fully automatic, and it provides a fast, accurate and reproducible methodology to characterise the damage state in GFRP laminates in terms of transverse and off-axis cracks by detecting, counting, measuring and tracking. The robustness of the proposed ACC methodology has been validated through numerical simulation studies for varying crack densities, crack patterns and also fibre misalignment. The numerical simulation studies have further provided guidelines for the choice of measuring volume as function of camera resolution and ply thicknesses. The applicability, accuracy and robustness of the ACC methodology was further validated experimentally through tensile fatigue tests on [0/-60/0/60 $]_{\mathrm{s}}$ and $[0 /-30 / 0 / 30]_{\mathrm{s}}$ laminates. The developed ACC methodology enables fast and accurate determination of physical damage state parameters in GFRP laminates, and it is suggested this may be a useful tool for the development and validation of future reliable off-axis crack evolution and fatigue models.

\section{Acknowledgements}

The work presented was conducted as a part of a Ph.D. project at the Department of Mechanical and Manufacturing Engineering, Aalborg University, Denmark. The majority of the research was carried out during a visit of the corresponding author at the University of Southampton, Faculty of Engineering and the Environment. The project has received sponsorship from the Danish Agency for Science, Technology and Innovation. The support received is gratefully acknowledged.

\section{References}

[1] Shokrieh MM, Lessard LB. Progressive Fatigue Damage Modeling of Composite Materials, Part I: Modeling. J Compos Mater 2000;34:1056-80. doi:10.1177/002199830003401301.

[2] Eliopoulos EN, Philippidis TP. A progressive damage simulation algorithm for GFRP composites under cyclic loading. Part I: Material constitutive model. Compos Sci Technol 2011;71:742-9. doi:10.1016/j.compscitech.2011.01.023.

[3] Sun XS, Haris A, Tan VBC, Tay TE, Narasimalu S, Della CN. A multi-axial fatigue model for fiber-reinforced composite laminates based on Puck's criterion. J Compos Mater 
Glud, J.A., Overgaard, L.C.T., Dulieu-Barton, J.M., and Thomsen, O.T., “Automated counting of off-axis tunnelling cracks using digital image processing” Composites

Science and Technology, 125, 2016, 80-89. http://dx.doi.org/10.1016/j.compscitech.2016.01.019

2012;46:449-69. doi:10.1177/0021998311418701.

[4] Kennedy CR, Brádaigh CMÓ, Leen SB. A multiaxial fatigue damage model for fibre reinforced polymer composites. Compos Struct 2013;106:201-10.

doi:10.1016/j.compstruct.2013.05.024.

[5] Hashin Z, Rotem A. A Fatigue Failure Criterion for Fiber Reinforced Materials. J Compos Mater 1973;7:448-64. doi:10.1177/002199837300700404.

[6] Quaresimin M, Susmel L, Talreja R. Fatigue behaviour and life assessment of composite laminates under multiaxial loadings. Int J Fatigue 2010;32:2-16.

doi:10.1016/j.ijfatigue.2009.02.012.

[7] Lundmark P, Varna J. Constitutive Relationships for Laminates with Ply Cracks in Inplane Loading. Int J Damage Mech 2005;14:235-59. doi:10.1177/1056789505050355.

[8] Singh C V, Talreja R. A synergistic damage mechanics approach for composite laminates with matrix cracks in multiple orientations. Mech Mater 2009;41:954-68.

doi:10.1016/j.mechmat.2009.02.008.

[9] Carraro PA, Quaresimin M. A stiffness degradation model for cracked multidirectional laminates with cracks in multiple layers. Int J Solids Struct 2015;58:34-51.

doi:10.1016/j.ijsolstr.2014.12.016.

[10] Emery TR, Dulieu-Barton JM. Thermoelastic Stress Analysis of damage mechanisms in composite materials. Compos Part A Appl Sci Manuf 2010;41:1729-42.

doi:10.1016/j.compositesa.2009.08.015.

[11] Battams G. The Use Of Optical Techniques To Assess The Damage Tolerance Of Composite Materials. University of Southampton, 2014.

[12] Li L, Lomov S V, Yan X, Carvelli V. Cluster analysis of acoustic emission signals for 2D and 3D woven glass/epoxy composites. Compos Struct 2014;116:286-99.

doi:10.1016/j.compstruct.2014.05.023.

[13] Guild FJ, Vrellos N, Drinkwater BW, Balhi N, Ogin SL, Smith PA. Intra-laminar cracking in CFRP laminates: observations and modelling. J Mater Sci 2006;41:6599-609.

doi:10.1007/s10853-006-0199-0. 
Glud, J.A., Overgaard, L.C.T., Dulieu-Barton, J.M., and Thomsen, O.T., “Automated counting of off-axis tunnelling cracks using digital image processing” Composites

Science and Technology, 125, 2016, 80-89. http://dx.doi.org/10.1016/j.compscitech.2016.01.019

[14] Sket F, Enfedaque A, Alton C, González C, Molina-Aldareguia JM, Llorca J. Automatic quantification of matrix cracking and fiber rotation by X-ray computed tomography in shear-deformed carbon fiber-reinforced laminates. Compos Sci Technol 2014;90:12938. doi:10.1016/j.compscitech.2013.10.022.

[15] Wharmby A. Observations on damage development in fibre reinforced polymer laminates under cyclic loading. Int J Fatigue 2003;25:437-46. doi:10.1016/s01421123(02)00118-4.

[16] Wharmby AW, Ellyin F. Damage growth in constrained angle-ply laminates under cyclic loading. Compos Sci Technol 2002;62:1239-47. doi:10.1016/s0266-3538(02)00075-1.

[17] Adden S, Horst P. Stiffness degradation under fatigue in multiaxially loaded noncrimped-fabrics. Int J Fatigue 2010;32:108-22. doi:10.1016/j.ijfatigue.2009.02.002.

[18] Quaresimin M, Carraro PA, Mikkelsen LP, Lucato N, Vivian L, Brøndsted P, et al. Damage evolution under cyclic multiaxial stress state: A comparative analysis between glass/epoxy laminates and tubes. Compos Part B Eng 2014;61:282-90. doi:10.1016/j.compositesb.2014.01.056.

[19] Wolodko JD, Hoover JW, Ellyin F. Detection of transverse cracks in GFRP composites using digital image processing. In: Ellyin F, Provan JW, editors. Prog. Mech. Behav. Mater. (ICM8), VOL 2 Mater. Prop., Univ Alberta, Dept Mech Engn, Edmonton, AB T6G 2G8, Canada.: UNIV VICTORIA, DEPT MECH ENGN, VICTORIA, BC V8W 3P6, CANADA; 1999, p. 483-7.

[20] Lewis JP. Fast normalized cross-correlation. Vis Interface 1995;10:120-3.

[21] Daugman JG. Uncertainty relation for resolution in space, spatial frequency, and orientation optimized by two-dimensional visual cortical filters. JOSA A 1985;2:1160-9.

[22] Otsu N. A threshold selection method from gray-level histograms. IEEE Trans Syst Man Cybern 1979;9:62-6.

[23] Lam L, Lee SW, Suen C. Thinning methodologies: a comprehensive survey. IEEE Trans Pattern Anal Mach Intell 1992;14:869-85.

[24] Tong J, Guild FJ, Ogin SL, Smith PA. On matrix crack growth in quasi-isotropic laminates-I. Experimental investigation. Compos Sci Technol 1997;57:1527-35. 
Glud, J.A., Overgaard, L.C.T., Dulieu-Barton, J.M., and Thomsen, O.T., “Automated counting of off-axis tunnelling cracks using digital image processing” Composites

Science and Technology, 125, 2016, 80-89. http://dx.doi.org/10.1016/j.compscitech.2016.01.019

doi:10.1016/s0266-3538(97)00080-8.

[25] Lafarie-Frenot MC, Hénaff-Gardin C. Formation and growth of $90^{\circ}$ ply fatigue cracks in carbon/epoxy laminates. Compos Sci Technol 1991;40:307-24. doi:10.1016/02663538(91)90087-6.

[26] Varna J. Modelling mechanical performance of damaged laminates. J Compos Mater 2013;47:2443-74. doi:10.1177/0021998312469241. 
Glud, J.A., Overgaard, L.C.T., Dulieu-Barton, J.M., and Thomsen, O.T., “Automated counting of off-axis tunnelling cracks using digital image processing” Composites

Science and Technolıgy, 125, 2016, 80-89. http://dx.doi.org/10.1016/j.compscitech.2016.01.019

(a)

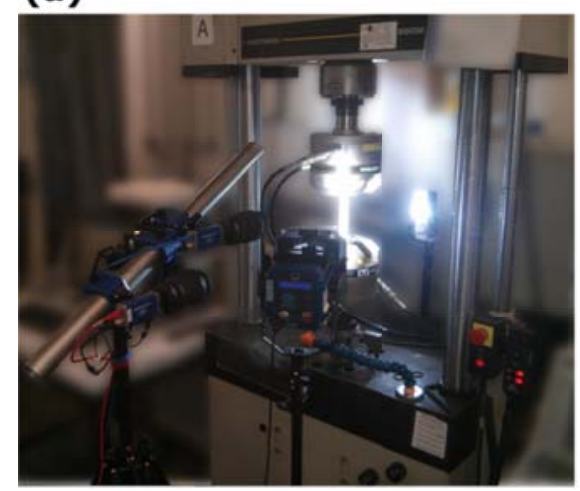

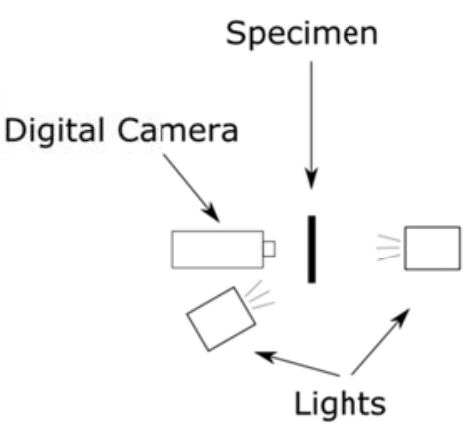

(b)

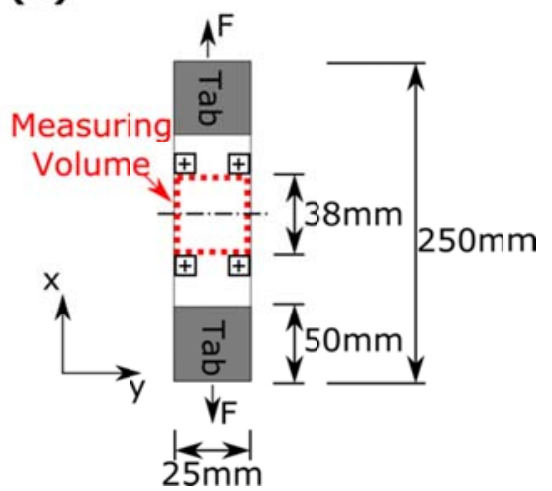

Figure 1: (a) Experimental setup. (b) Specimen, measuring volume and marker positions.

(a)

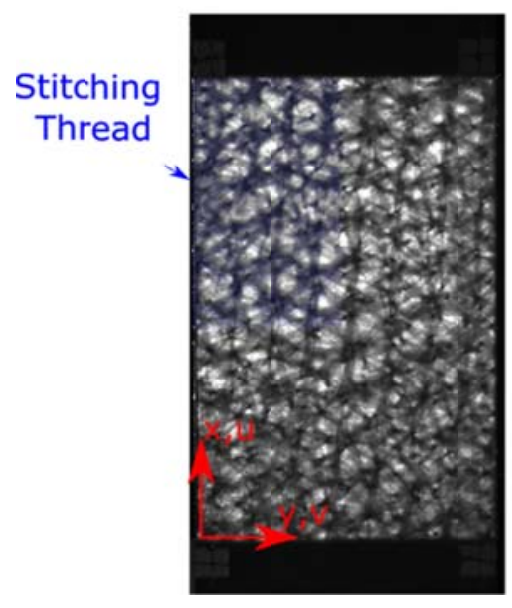

(b)

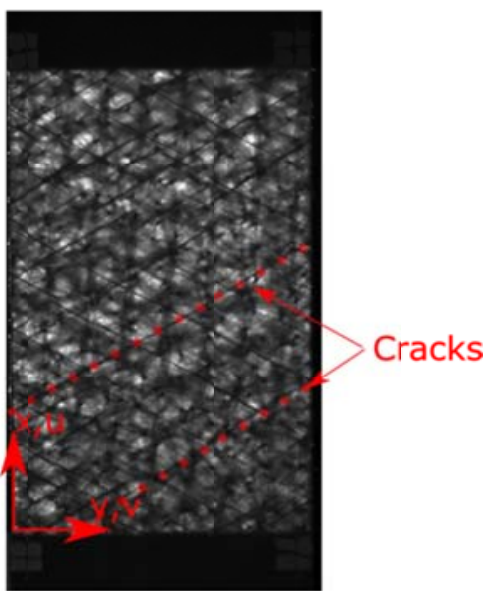

Figure 2: (a) Measuring volume seen by digital camera. Stitching thread is highlighted with blue.

(b) In-situ observation of off-axis.

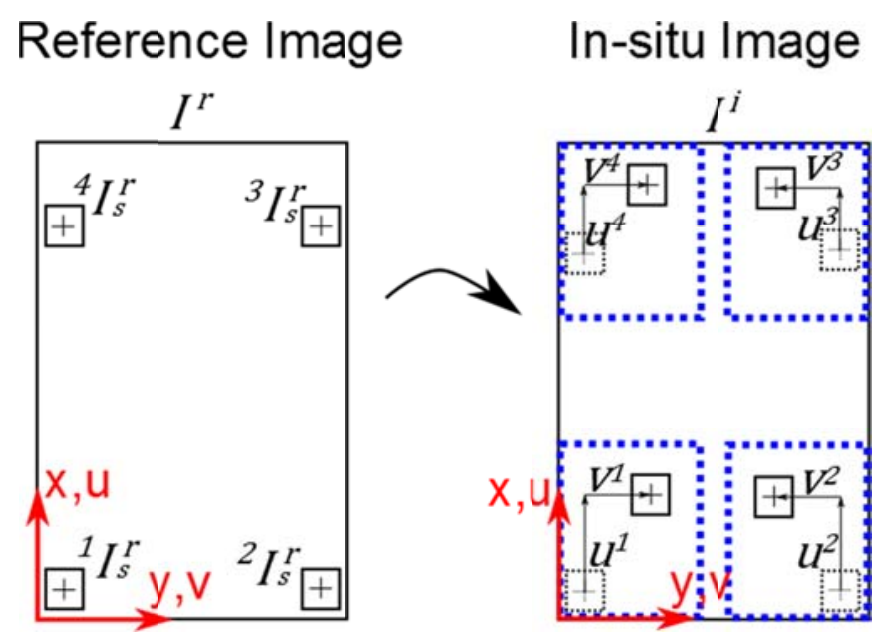

Figure 3: Features defined in the reference image and afterwards found in the in-situ image. 
Glud, J.A., Overgaard, L.C.T., Dulieu-Barton, J.M., and Thomsen, O.T., “Automated counting of off-axis tunnelling cracks using digital image processing” Composites

Science and Technology, 125, 2016, 80-89. http://dx.doi.org/10.1016/j.compscitech.2016.01.019

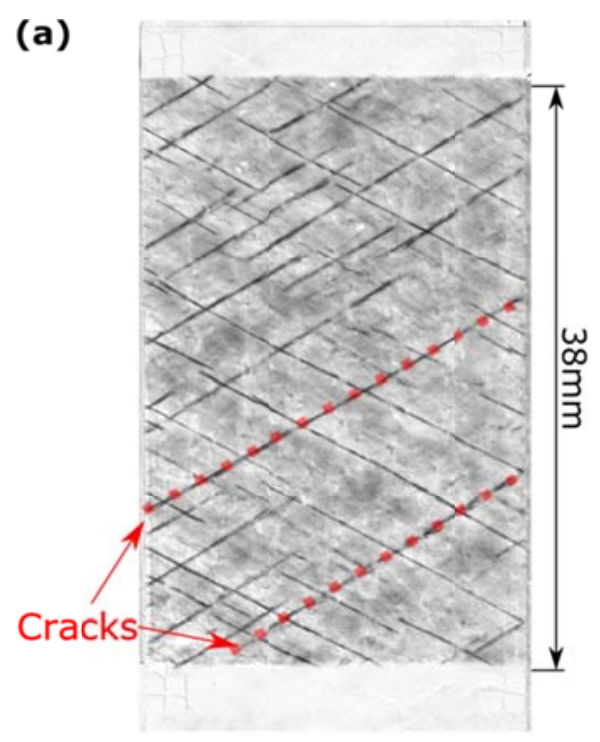

\section{(b)}

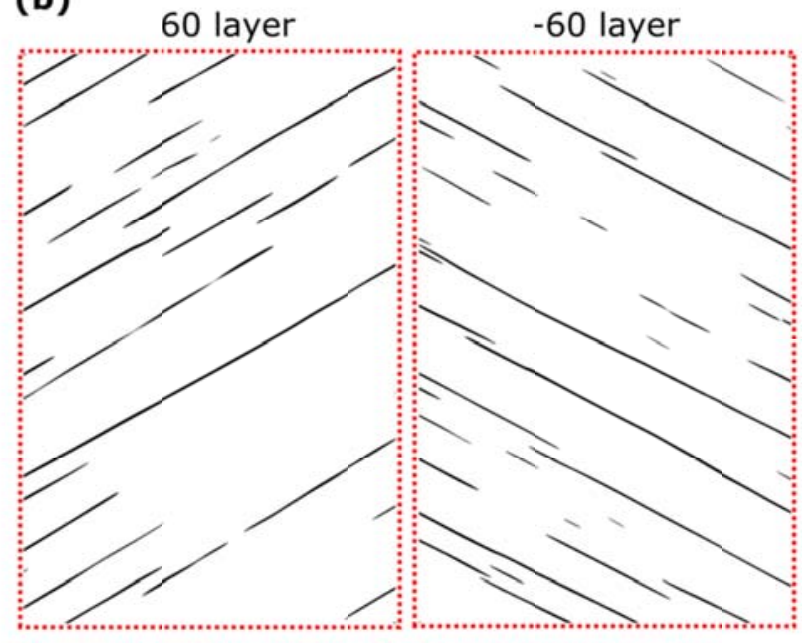

Figure 4: a) Result of normalising the compensated in-situ image $\left(I^{u}\right)$ with the reference image $\left(I^{r}\right)$ to give $I^{d}$. b) Gabor filtering of $I^{d}$ Figure 4 a for each orientation of off-axis cracks.

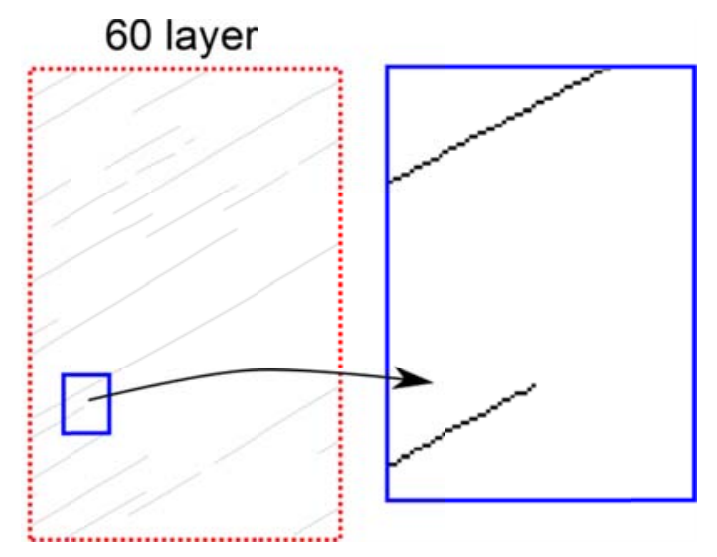

Figure 5: Cracks for 60 degree layer as seen in Figure 4b condensed into one pixel thick lines using the thinning algorithm from [22]. 
Glud, J.A., Overgaard, L.C.T., Dulieu-Barton, J.M., and Thomsen, O.T., “Automated counting of off-axis tunnelling cracks using digital image processing” Composites

Science and Technology, 125, 2016, 80-89. http://dx.doi.org/10.1016/j.compscitech.2016.01.019

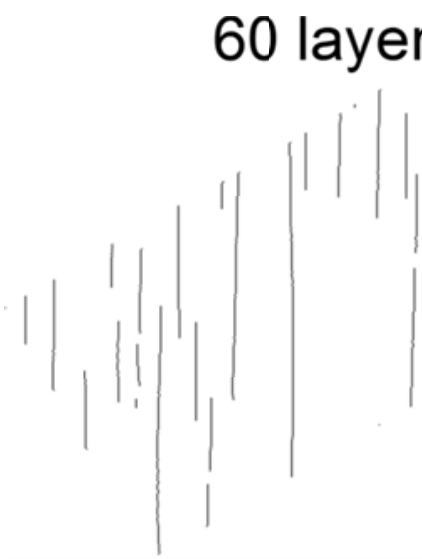

-60 layer

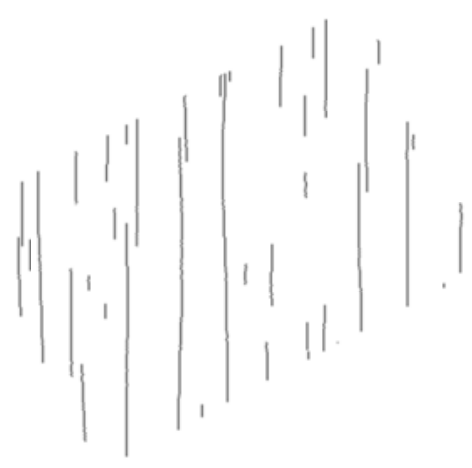

Figure 6: Cracks rotated to vertical direction to facilitate counting procedure.

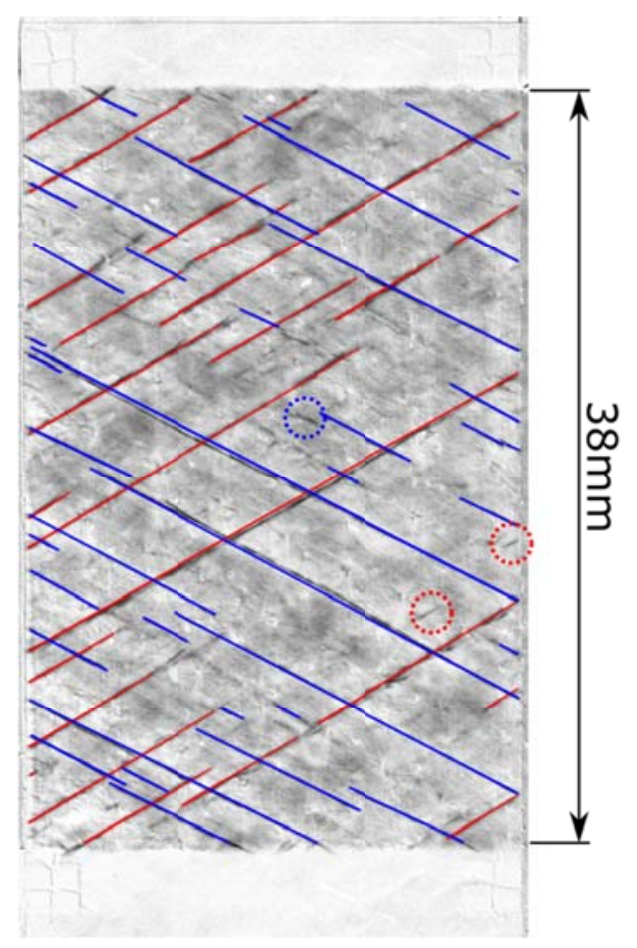

Figure 7: Cracks counted by ACC of image given in Figure 4a (blue is - 60 degree layer, red is +60 degree layer). 
Glud, J.A., Overgaard, L.C.T., Dulieu-Barton, J.M., and Thomsen, O.T., “Automated counting of off-axis tunnelling cracks using digital image processing” Composites

Science and Technolıgy, 125, 2016, 80-89.

http://dx.doi.org/10.1016/j.compscitech.2016.01.019

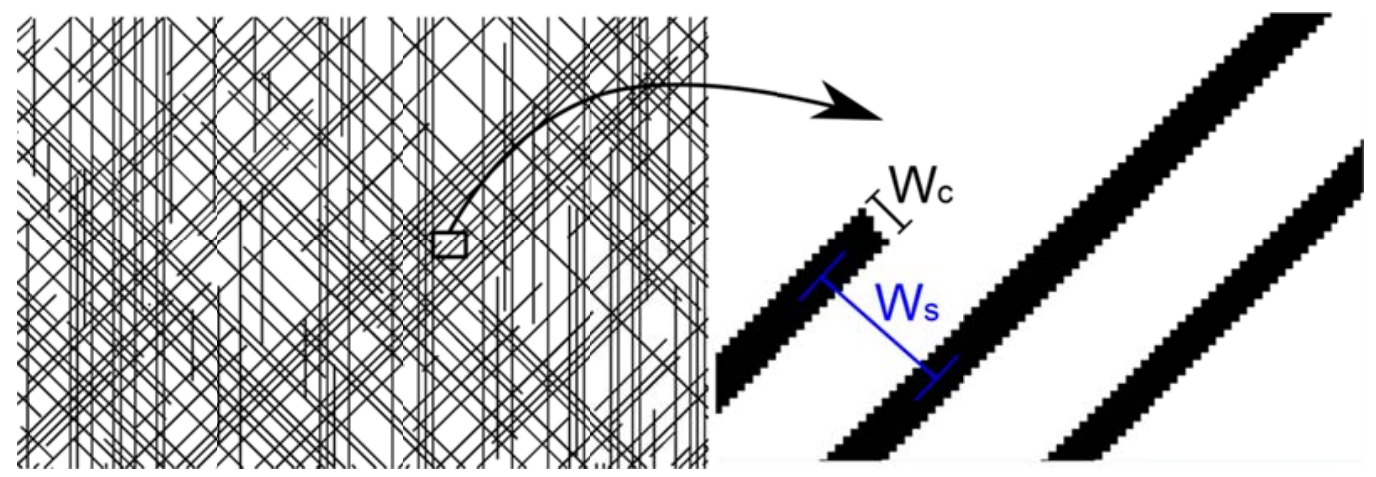

Figure 8: Illustration of simulated cracks in [-45/45/90] laminate. The simulated crack density for each orientation is 0.018 [cracks/pixel].

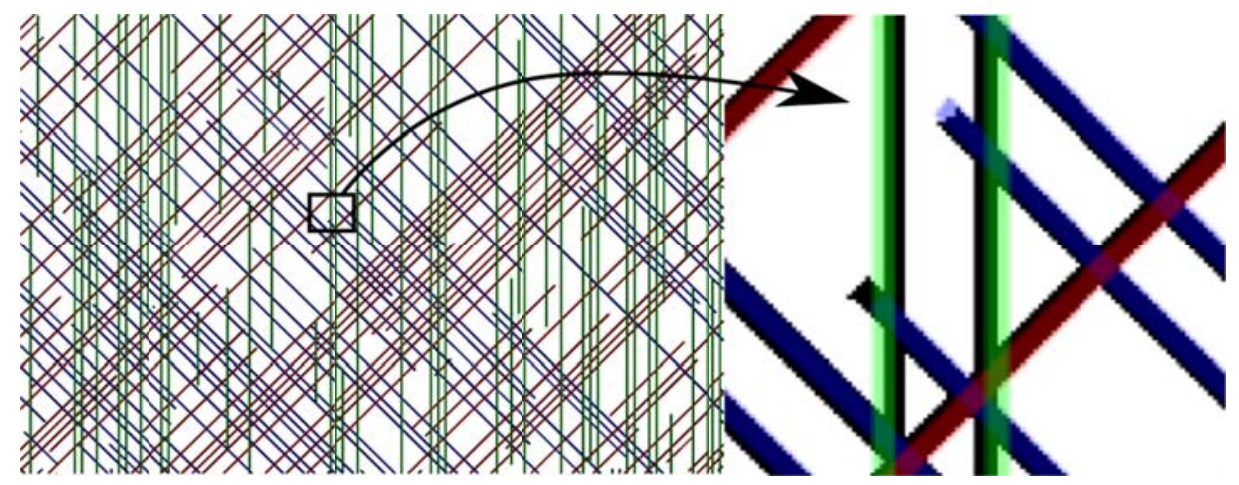

Figure 9: Cracks in simulated [-45/45/90] laminate counted by ACC. Blue, red and green refer to the $-45,45$ and 90 layers, respectively.

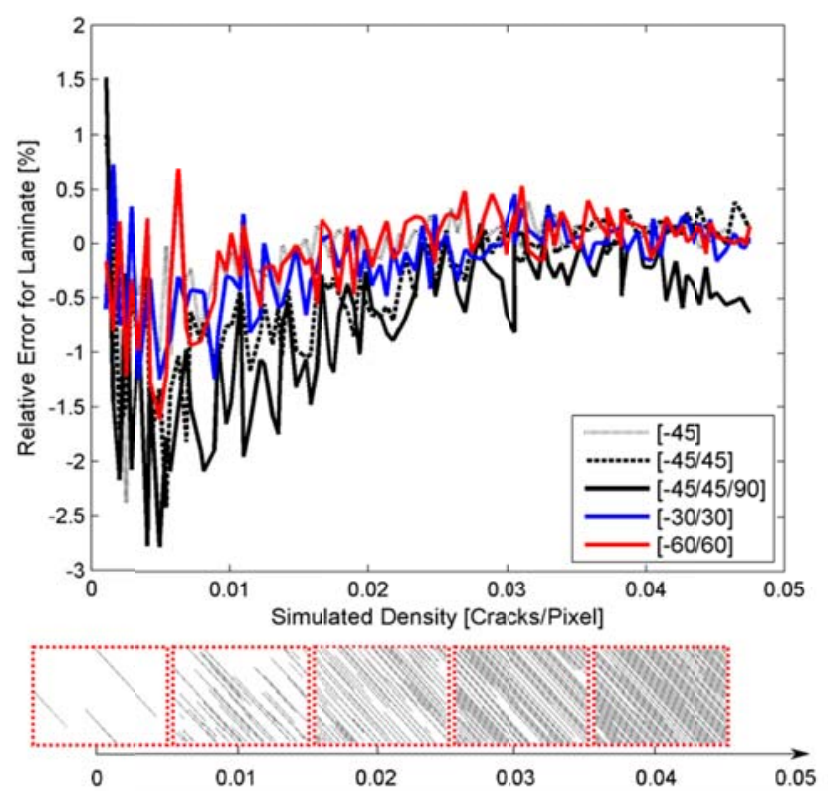


Glud, J.A., Overgaard, L.C.T., Dulieu-Barton, J.M., and Thomsen, O.T., “Automated counting of off-axis tunnelling cracks using digital image processing” Composites

Science and Technolıgy, 125, 2016, 80-89. http://dx.doi.org/10.1016/j.compscitech.2016.01.019

Figure 10: Relative error of laminate between counted crack density and artificial crack density with examples of the artificial images for increasing crack density in one ply.

(a)

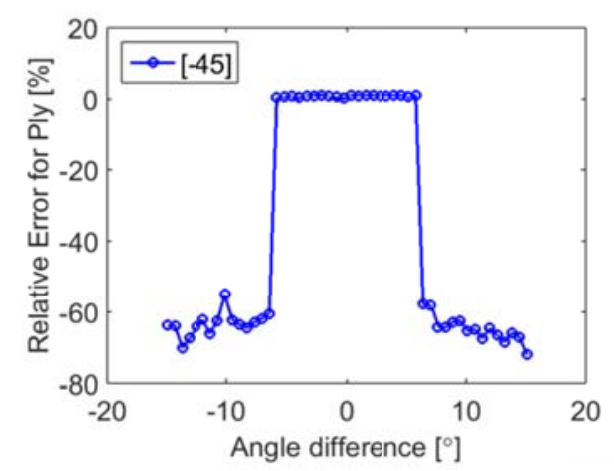

(b)

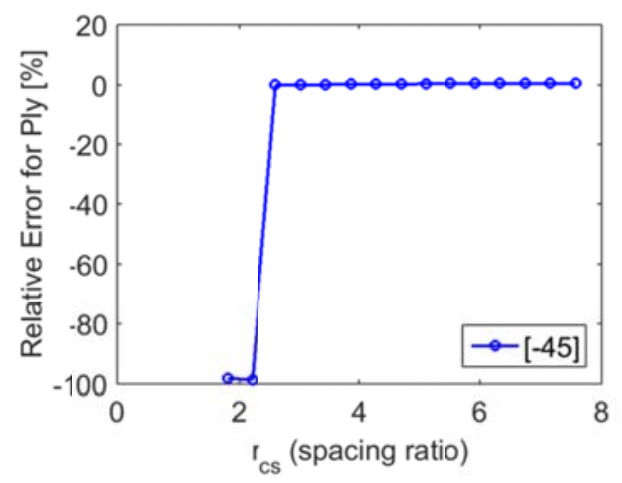

Figure 11: (a) Relative error of crack density as a function of the difference between the ply angle in the artificial image and the user specified angle. (b) Relative error of measured crack density as function of crack spacing.

(a)

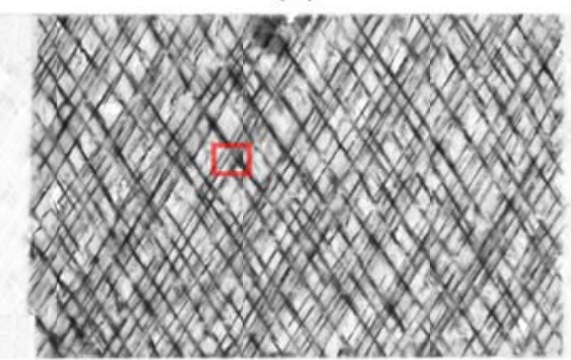

(c)

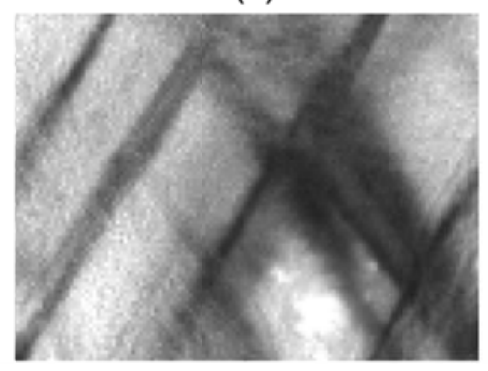

(b)

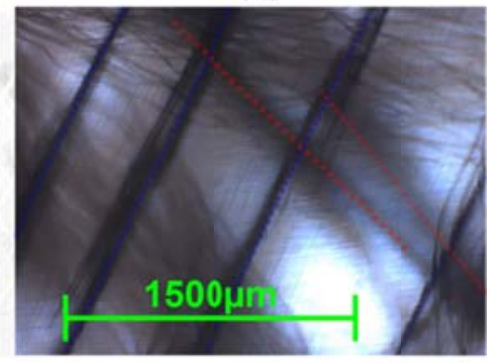

(d)

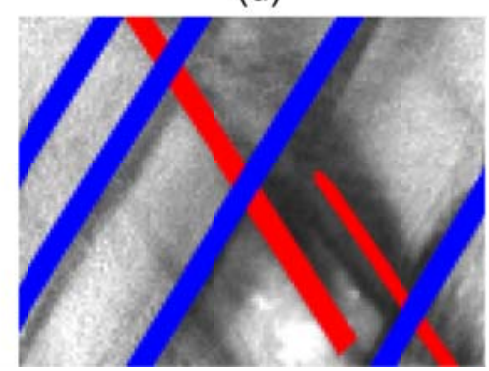

Figure 12: [0/-60/0/60] laminate: Comparison of cracks counted by the ACC algorithm and cracks seen in the microscope. (a) Complete measuring volume with the area of interest marked, (b) Area of interest as seen by microscope at $4 x$ zoom, (c) Area of interest seen by digital camera using the image compensation procedure, and (d) Cracks counted by the ACC algorithm. 
Glud, J.A., Overgaard, L.C.T., Dulieu-Barton, J.M., and Thomsen, O.T., “Automated counting of off-axis tunnelling cracks using digital image processing” Composites

Science and Technolıgy, 125, 2016, 80-89. http://dx.doi.org/10.1016/j.compscitech.2016.01.019

(a)

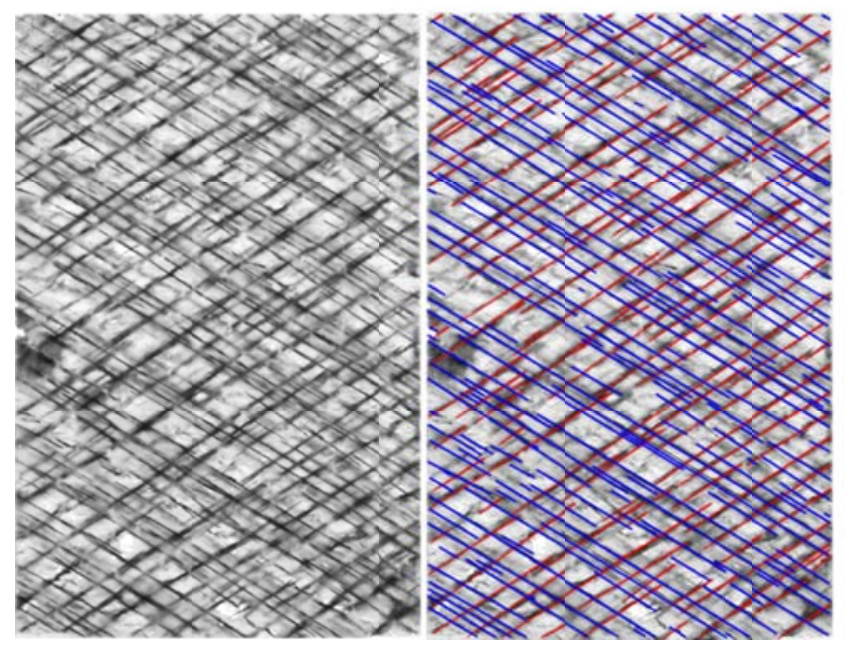

(c)

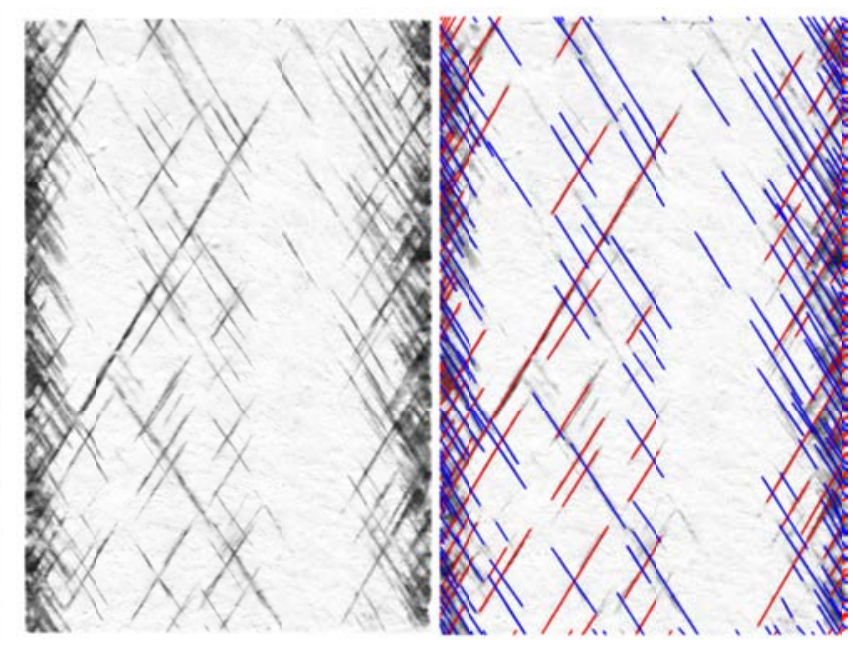

Figure 13: Cracks counted by the ACC algorithm at end of the fatigue test for (a)-(b) the [0/60/0/60]s laminate and (c)-(d) the [0/-30/0/30]s laminate.

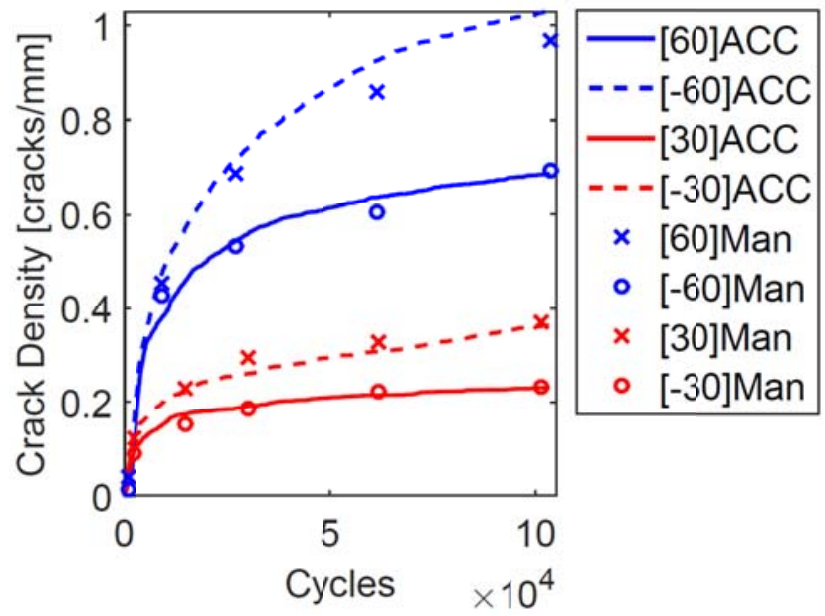

Figure 14: Crack density as function of number of fatigue cycles measured for the different layers during the fatigue life using ACC and Manual counting (Man). 